\title{
Development and organization of polarity-specific segregation of primary vestibular afferent fibers in mice
}

\author{
Adel Maklad • Suzan Kamel • Elaine Wong • \\ Bernd Fritzsch
}

Received: 15 October 2009 /Accepted: 4 February 2010

(C) Springer-Verlag 2010

\begin{abstract}
A striking feature of vestibular hair cells is the polarized arrangement of their stereocilia as the basis for their directional sensitivity. In mammals, each of the vestibular end organs is characterized by a distinct distribution of these polarized cells. We utilized the technique of post-fixation transganglionic neuronal tracing with fluorescent lipid soluble dyes in embryonic and postnatal mice to investigate whether these polarity characteristics correlate with the pattern of connections between the endorgans and their central targets; the vestibular nuclei and cerebellum. We found that the cerebellar and brainstem projections develop independently from each other and have a non-overlapping distribution of neurons and affer-
\end{abstract}

This work was supported by a grant from the Egyptian Government (GM-098; A.M.), by a NASA grant (NAG 2-1353; B.F. and A.M.), and by NIH grant (2R01 DC005590; B.F.).

\section{A. Maklad $(\square)$}

Department of Anatomy,

University of Mississippi Medical Center,

Jackson, MS 39216, USA

e-mail: amaklad@anatomy.umsmed.edu

\section{S. Kamel}

Department of Oral Biology, University of Missouri,

Kansas, MO 64108, USA

E. Wong $\cdot$ B. Fritzsch

Department of Biology, University of Iowa,

Iowa, IA 52242, USA

\author{
A. Maklad $\cdot$ S. Kamel \\ Assiut University School of Medicine, \\ Assiut, Egypt \\ E. Wong \\ University of Hong Kong, \\ Hong Kong, China
}

ents from E11.5 on. In addition, we show that the vestibular fibers projecting to the cerebellum originate preferentially from the lateral half of the utricular macula and the medial half of the saccular macula. In contrast, the brainstem vestibular afferents originate primarily from the medial half of the utricular macula and the lateral half of the saccular macula. This indicates that the line of hair cell polarity reversal within the striola region segregates almost mutually exclusive central projections. A possible interpretation of this feature is that this macular organization provides an inhibitory side-loop through the cerebellum to produce synergistic tuning effects in the vestibular nuclei. The canal cristae project to the brainstem vestibular nuclei and cerebellum, but the projection to the vestibulocerebellum originates preferentially from the superior half of each of the cristae. The reason for this pattern is not clear, but it may compensate for unequal activation of crista hair cells or may be an evolutionary atavism reflecting a different polarity organization in ancestral vertebrate ears.

Keywords Cerebellum · Development · Hair cells . Macula $\cdot$ Crista $\cdot$ Mouse $(\mathrm{CF} 1)$

$\begin{array}{ll}\text { Abbreviations } \\ \text { AC } & \text { Anterior canal crista } \\ \text { BST } & \text { Brainstem } \\ \text { CB } & \text { Cerebellum } \\ \text { HC } & \text { Horizontal canal } \\ \text { IN } & \text { Intermediate nerve } \\ \text { IVG } & \text { Inferior vestibular ganglion } \\ \text { LPR } & \text { Line of polarity reversal } \\ \text { PC } & \text { Posterior canal crista } \\ \text { r4 } & \text { Rhombomere 4 } \\ \text { SA } & \text { Saccular macula } \\ \text { SVG } & \text { Superior vestibular ganglion } \\ \text { UT } & \text { Utricular macula }\end{array}$


VNC Vestibular nuclear complex

$\mathrm{V} \quad$ Trigeminal nerve

VII Facial nerve

VIII Vestibulocochlear nerve

IX Glossopharyngeal nerve

\section{Introduction}

The vestibular system in mammals has five sensory endorgans: three semicircular canals that detect angular acceleration, and the utricle and saccule which function as linear acceleration and gravistatic detectors (Wilson 1972; Goldberg 1981). The geometrical organization and spatial placement of sensory patches within the endorgans, including their hair cell polarity and their pattern of connectivity with afferent neurons, are of the utmost physiological importance to the function of the vestibular system. These parameters determine the directional sensitivity of an endorgan to head motion and position in a given plane (Lowenstein 1961; Wersäll 1961; Flock 1964; Hudspeth and Corey 1977; Hudspeth and Jacobs 1979; Shotwell et al. 1981; Lewis et al. 1985).

The sensory vestibular information, encoded by hair cells, is conveyed by primary vestibular neurons to secondary vestibular neurons. These secondary vestibular neurons are organized into functional groups which project to different targets, eliciting appropriate motor responses (Büttner-Ennever 1999; for review). The general and endorgan-specific nature of the central projections of the primary vestibular afferents have been studied in several vertebrates, using different methods (Cajal 1896; Lorente de No 1933; Korte and Mugnaini 1979; Carpenter et al. 1972; Maklad and Fritzsch 2002, 2003a; Newlands et al. 2002). It is now known that the canals and otolith organs project to the vestibular nuclear complex in the brainstem and cerebellum in specific manners that characterize each endorgan (Maklad and Fritzsch 2003b; Newlands and Perachio 2003; for review). It is also known that different classes of afferents and their associated terminals are distributed within the vestibular sensory epithelia in a topographically organized fashion that reflects morphophysiologic characteristics of those afferents (Fernández et al. 1990; Goldberg et al. 1990; Zakir et al. 2003; Haque et al. 2006). However, little is known about the peripheral distribution of these afferents within the neuroepithelium with respect to their central terminations. Purcell and Perachio (2001) attempted to elucidate the origin of the primary vestibular afferents projecting to the cerebellum in the peripheral endorgans. They suggested that primary vestibular afferents to the vestibulocerebellum derive mainly from the peripheral zones of the canals' epithelia and peristriola region in the otolith endorgans (utricle and saccule). Their analysis did not include primary afferents to the brainstem. It is not known whether the vestibular afferents to the brainstem follow a similar, topologically restricted distribution that mirrors the cerebellar afferents.

Another outstanding issue of the vestibular system is the function of hair cell polarity reversal in the otolith organs. Vestibular hair cells are tuned for a specific direction of activation and inactivation due to the graded heights of their stereocilia and the presence of a kinocilium which gives them functional polarity. In a given semicircular canal crista, all hair cells have the same polarity. However, in each coplanar pair of canals, the hair cells of each canal display opposing polarities and best activation directions with respect to the other (Wersäll and Flock 1963; Flock 1964; Wersäll et al. 1965). Consequently, with rotation in a canal plane, the activity conveyed via canal afferents to the two sides of the brainstem is modulated in opposite directions (Precht and Shimazu 1965; Straka and Dieringer 1996, 2000). This central tuning effect is further accentuated by the presence of commissural inhibitory neurons connecting the vestibular nuclei on both sides of the brainstem (Shimazu and Precht 1966; Walberg et al. 1990; Reichenberger et al. 1997; Holstein et al. 1999; Holler and Straka 2001).

In the otolith endorgans (utricle and saccule), the stereociliary bundles of the hair cells within each macula have varying polarities representing most orientations in space. Each given orientation is represented by two populations of the hair cells of opposing polarities with mirror-image symmetry along a line known as the line of polarity reversal (LPR) within the striola region (Flock 1964; Lindeman 1969). Functionally, the presence of two opposing polarities implies that each otolith, in contrast to the canals, sends two oppositely tuned inputs to the ipsilateral brainstem when stimulated (Lowenstein 1961; Lindeman 1969). The functional significance of this mirrorimage organization of hair cells with opposing polarity and resultant contradictory inputs is unknown. In the curved utricle and saccule, one half of the macula (a hemi-macula), within which hair cells display all possible polarities, is theoretically sufficient to encode all vectors of directional responsiveness. The question as to what function might two hemi-maculae of opposing polarity have, and what the oppositely tuned output possibly serve, remains open. Likewise, whether this polarity characteristic in the otolith endorgans influences the central distribution of vestibular afferents is unknown. It is plausible to assume that these outputs of opposite polarities do not converge centrally on the same set of central target neurons, otherwise they would tend to nullify each other.

Electrophysiological recordings from secondary vestibular neurons support the existence of polarity-specific 
segregation of the macular afferents onto inhibitory interneurons in the vestibular nuclear complex (VNC). This circuit induces "cross-striolar inhibition" which unilaterally provides facilitation/disinhibition coupling and increases the sensitivity and noise resistance of the secondary vestibular neurons (Uchino et al. 1997, 1999). However, in Uchino's experiments, all recordings from secondary vestibular neurons were made after stimulation of two focal points on both sides of the striola (medial and lateral extrastriolar regions). Afferents contacting all hair cells across striola were not systematically stimulated to test whether these hair cells associated afferents on one side of the striola project to inhibitory interneurons or other central targets such as the cerebellum. To date, no neuroanatomical approach was used to address this issue. Here, we employed transganglionic neuroanatomical tracers to label primary afferent fibers connecting the vestibular end organs to the cerebellum and vestibular nuclear complex. Our results demonstrate a hitherto unknown developmental segregation of specific hair cell polarity connecting afferents in the utricular and saccular maculae with respect to cerebellar and brainstem projections. Our embryonic data indicate that each vestibular epithelium is innervated by two distinct neuronal populations that project specifically either to the cerebellum or brainstem from the outset.

\section{Materials and methods}

Mice were harvested from a breeding colony of a CF1 outcross strain (Jackson Laboratory, Bar Harbor, Maine). Embryos were harvested at embryonic days 11.5, 13.5, 14.5, 15.5, and 16.5, and designated as E11.5, E13.5, E14.5, E15.5, and E16.5, with noon after conception designated as embryonic day (E0.5). Postnatal age groups were harvested as newborn and were designated as postnatal day 0 (P0), 7-day-old (P7), and 21-day-old weanlings (P21). All experiments were conducted in accordance with NIH guidelines for animal care and use, and approved by Creighton University and the University of Mississippi Animal Care and Use Committees.

Detailed analyses of afferent segregation were performed at birth and P7 where the tracers employed work optimally for reliable analysis. Pups were deeply anesthetized by intraperitoneal injection of pentobarbital sodium $(0.1 \mathrm{mg} / \mathrm{kg})$ and then perfused through the heart with $4 \%$ paraformaldehyde in phosphate-buffered saline (PBS). The pups were decapitated, their scalps were removed, and their calvaria were opened to expose the brain to the fixative. The heads were postfixed in $4 \%$ paraformaldehyde in PBS for at least $72 \mathrm{~h}$. The heads were then bisected in the mid-sagittal plane through the cerebellum and the brainstem to expose the vermal lobules of the cerebellum. This approach permitted clear identification of the different vermal lobules with certainty.

In P0 pups, we employed single and double labeling techniques. In one group, DiI-loaded filter strips (Invitrogen, Carlsbad, CA) were implanted in the core of both the uvula and nodulus to target the primary vestibulocerebellar afferent axons. In a second group, Dil-loaded filter strips were implanted in the brainstems to target the primary vestibular afferents projecting to the brainstem. The DiI-filter strips were cut in such a way that they were as long as the entire length but half the width of the medulla. In a third group, DiIloaded filter strips were implanted in the brainstem (Fig. 1a), and Neuro-Vue Maroon-loaded filter strips (Molecular Targeting Technologies, Westchester, PA) were implanted in the white matter core of the uvula and nodulus of the cerebellum (Fig. 1a). This double labeling allowed us to examine the peripheral origin of each projection within the context of the other, and locate the peripheral boundaries between the two projections. In the double labeling procedure, we implanted the NeuroVue Maroon 3 days ahead of implanting DiI in the brainstem to accommodate the longer distance of the primary vestibulocerebellar projection.

In P7 pups, we employed double labeling experiments as in PO. NeuroVue Maroon-loaded filter strips were inserted in the uvula and nodulus, and in the same animals, a bulk implantation of DiI strips was made into the vestibular nuclear complex.

In E11.5 embryos, we applied a triple labeling by injecting three differently colored carbocyanine dyes: NeuroVue Maroon in the medulla, NeuroVue Jade in rhombomere 4, and NeuroVue Red into the cerebellum. For E13.5, E14.5, E15.5, E16.5, and P21, double labeling was used, implanting DiI in the brainstem and Neuro Vue Maroon in the cerebellum. All implantations in embryos were applied simultaneously and great care was taken to choose positions of approximately equal distance from the VIIIth nerve root.

All preparations were kept in 4\% paraformaldehyde in PBS, and incubated at $37^{\circ} \mathrm{C}$ for variable periods of time depending on the age examined (3-4 days for embryos, 1 week for P0, 4 weeks for P7, and 8 weeks for P21). After the appropriate diffusion times were completed, the inner ears were removed and their sensory epithelia were microdissected and mounted flat on slides. In E11.5 embryos, the entire heads were mounted flat on slides.

All preparations were whole-mounted in glycerol on a glass slide and examined with a confocal laser scanning system (Zeiss LSM 510 META NLO System; Zeiss, Thornwood, NY, BioRad, or Leica SPE confocal system). The excitation laser and emission filter settings for both tracers were used as described elsewhere (Maklad and Fritzsch 2002; Fritzsch et al. 2005b). Adjustments to 
Fig. 1 Experimental controls (implantation sites and the extent of tracers spread) are shown. a A stereoscopic image of a half brain cut at the midsagittal plane shows a DiI filter strip (red) implanted in the brainstem, and Neuro Vue Maroon (blue) filter strips implanted in the core of the uvula and nodulus. b A confocal image of a sagittal section of the brainstem shows the rostro-caudal extent of the tracer's spread. Note that the DiI is filling the entire medulla and caudal pons, and Neuro Vue Maroon is filling the entire uvula and nodulus. $\mathbf{c}$ A confocal image of a coronal section shows the extent of the tracers spread at the mediolateral axis in the brainstem and both uvula and nodulus. d,e,e' Confocal images of the trigeminal ganglion, facial nerve, geniculate ganglion, and nodose ganglion indicate a complete filling of the vestibular nuclear complex as demonstrated by the DiI spread beyond the vestibular nuclei to other cranial nerves. f A confocal image of the cochlea shows cochlear efferents anterogradely labeled from the brainstem. Cochlear afferents are not observed, indicating that the DiI diffusion in the brainstem did not involve the vestibulocochlear nerve root. Scale bars $1 \mathrm{~mm}$ in $(\mathbf{b}, \mathbf{c})$ and $100 \mu \mathrm{m}$ in $(\mathbf{d}-\mathbf{f})$
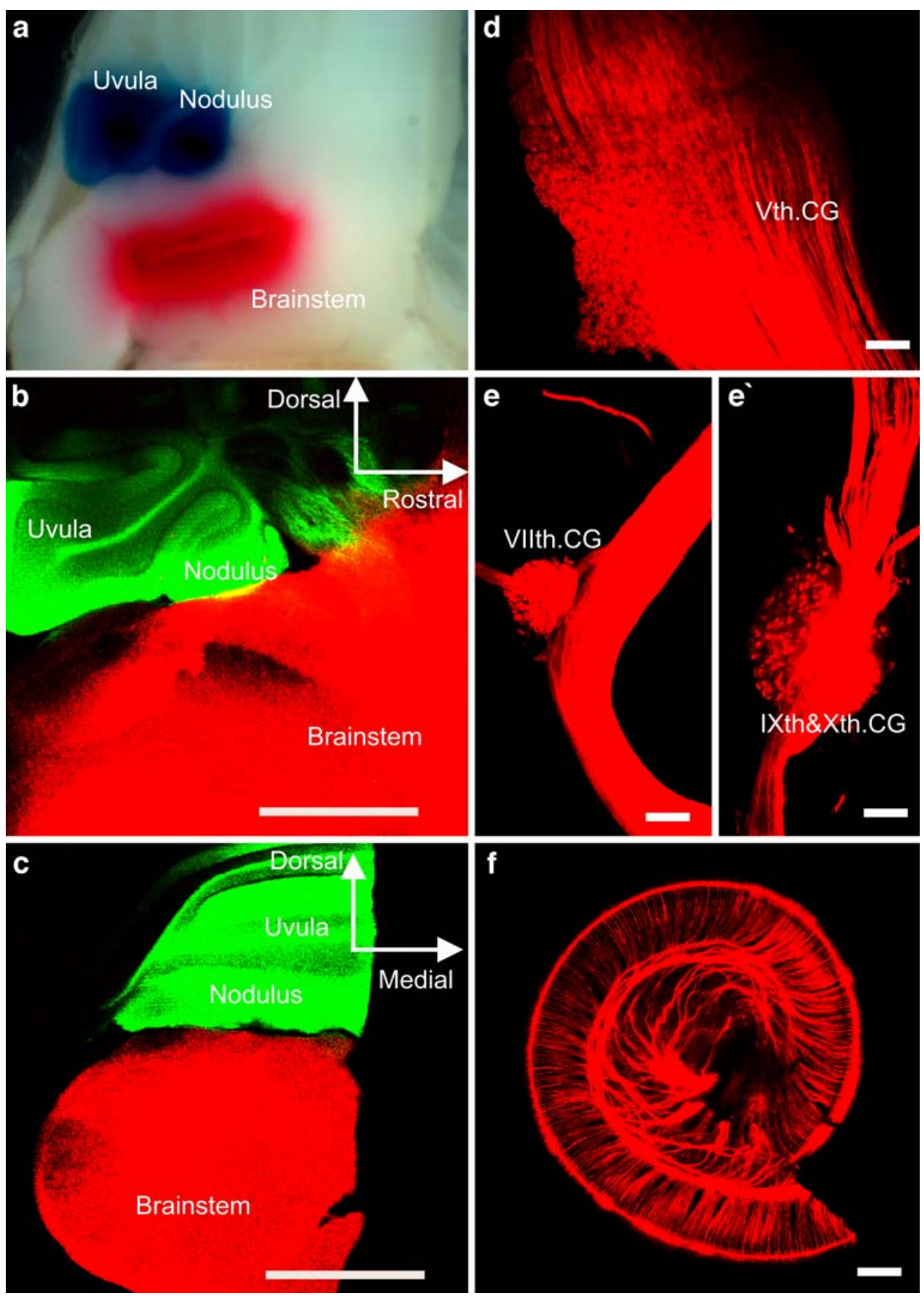

confocal images were only made with respect to uniform adjustments of brightness and overall color contrast. No pixel editing was made except to remove the magnification bar and replace it with uniform magnification bars since three different confocal systems were used during the duration of the study.

\section{Experimental controls}

Brainstems with their attached cerebella were embedded in gelatin and vibratome-sectioned, both sagittally and coro- nally, at $100-\mu m$-thick sections and examined by confocal microscopy. These preparations were used to verify that both the uvula and nodulus and all vestibular nuclei were completely filled with their respective tracers, leaving no false positive segregation of fibers in the peripheral endorgans. They also served as controls against false positive overlap due to local spread of the tracers between the VNC and cerebellum. Vestibular ganglia were also dissected out and examined as whole-mount preparations. Since we have bulk implantation in the brainstem, and this will likely diffuse to other cranial nerve nuclei, we 
examined cranial ganglia of the Vth, VIIth, IXth, and Xth cranial nerves as an indication of complete filling of the vestibular nuclear complex and beyond.

A major concern in the bulk implantation in the brainstem is the lateral spread of the tracer to the vestibular nerve root. In this case, the vestibular afferent fibers projecting to the cerebellum will be labeled from the tracer in the brainstem as well as from their respective tracer placed in the cerebellum, resulting in a false positive overlap. Since the cochlear nuclei lie lateral to and in the vicinity of the vestibular nerve root, all cochleas were examined to make sure that no retrogradely labeled cochlear afferents existed. Only cochlear efferents were labeled through the olivo-cochlear bundle from the brainstem. Preparations with labeled cochlear afferents were discarded from subsequent analysis.

Since this is the first report to use retrograde double labeling approach to study the peripheral distribution of the vestibular afferents, it is possible that the peripheral pattern could be due to difference in the physical properties of the two tracers employed. To control against this possibility, in one group, the same double labeling protocol was employed, except with reversed implantation sites. In this group, DiI was implanted in the cerebellum and Neuro Vue Maroon was implanted in the uvula and nodulus. A mirrorimage reversal of colors would indicate a genuine anatomical pattern. Furthermore, a single DiI application in the brainstem in one group, and in the cerebellum in another, served as additional controls. At least 10 animals of successful tracer implantations and proper diffusions were used for analysis for each age group.

In nerve tracing experiments, the diffusion time is a crucial determinant of the outcome of the experiment. The optimal diffusion time for a given age group was determined based on a pilot experiment and our published observations (Maklad and Fritzsch 1999, 2002, 2003a). However, to ensure that the distribution pattern of retrogradely labeled afferents from the brainstem and cerebellum does not change with different diffusion times, a group of P7 animals that received double implantation was examined after two different time points around our defined optimal diffusion times. In one subgroup, endorgans were examined after 3 weeks, a week earlier than our optimal diffusion time. A second subgroup was examined after 5 weeks (a week past the optimum). Furthermore, DiI and Neuro Vue have similar diffusion speeds. However, the primary vestibulo-cerebellar afferents travel a longer distance than those primary afferents projecting to the brainstem. To accommodate for the longer distance of the primary vestibulo-cerebellar afferents, in the double labeling experiment, Neuro-Vue Maroon was implanted 3 days ahead of DiI implantation in the brainstem. These 3 days of longer diffusion were determined from DiI single cerebellar implantation experiments.

\section{Results}

\section{Control data}

Gross examination of the injected brainstems and cerebella under the dissecting microscope (Fig. 1a), as well as examination of their sagittal and coronal sections of the brainstems and cerebella (Fig. 1b and c, respectively) revealed that the brainstems were almost completely filled by the tracer (DiI, false-colored red) from the mid-pons to the caudal medulla, including the entire vestibular nuclear complex. The tracer's spread beyond the vestibular nuclear complex to other cranial nerve nuclei was evident as indicated by the presence of retrograde labeling in the cranial ganglia of the Vth, VIIth, IXth, and Xth cranial nerves (Fig. 1d, e, and e', respectively). The uvula and nodulus of the cerebellum were completely filled with the Neuro Vue Maroon (Fig. 1a, b, c, false-colored blue and green, respectively). There was no local spread of the DiI to the cerebellum nor Neuro Vue Maroon to the brainstem. Examination of cochleas revealed labeled efferents from the olivo-cochlear bundle, with a complete absence of any labeling in the cochlear afferents. In all cochleas examined, there were no fibers labeled with Neuro Vue Maroon from the cerebellum (Fig. 1f).

In double labeling experiments, DiI was routinely implanted in the brainstem and Neuro Vue Maroon was implanted in the cerebellum. These implantation sites resulted in cerebellar afferents labeling (green) lateral to the line of polarity reversal (LPR) within the striola region (Fig. 2a; dotted curved line) in the utricular macula (UT), and medial to the LPR (Fig. 2 a'; dotted curved line) in the saccular macula (SA). In contrast, afferents labeled from the brainstem (red) were medial to the LPR in the utricular macula and lateral to it in the saccular macula. In both endorgans, a population of yellow-stained fibers and terminals were seen on either side of LPR. This yellowstained population was more obvious when a z-series of images was collapsed into a single 2D-image as those presented in Fig. 2 and thereafter. To be certain that the peripheral pattern obtained from the retrograde doubletracers was not an artifact due to differences in the physical properties of the two tracers employed, we reversed the implantation site of the two tracers in some preparations (DiI in the cerebellum and Neuro Vue Maroon in the brainstem). In these experiments, similar fiber segregation patterns were reproduced, albeit with a mirror-image reversal of the fluorescent red and green colors (Fig. 2b, b'). The yellow staining due to z-series collapse in both endorgans was also reproduced. This indicated that the peripheral segregation was not due to the uptake characteristics of the two tracers, but instead represents a genuine anatomical feature.

To verify that the diffusion time does not change the pattern of retrograde labeling, in one group the endorgans 
Fig. 2 Experimental controls (reversal of the tracers's implantation sites, and tracer diffusion time). a,a' confocal images of the utricular (UT) and saccular $(S A)$ maculae after DiI $($ red $)$ in the brainstem and Neuro Vue Maroon (green) in the cerebellum. Note that the cerebellar and brainstem afferents segregate at the line of polarity reversal (LPR); dotted curved lines. b,b' Confocal images of the utricular $(U T)$ and saccular $(S A)$ after reversal of the tracers' implantation sites (DiI in the cerebellum and Neuro Vue Maroon in the brainstem) show the same segregation pattern displayed in $(\mathbf{a}, \mathbf{a} ')$ with a mirror-image color reversal. c,c' Confocal images of utricular (UT) maculae examined after 3 and 5 weeks, respectively. Note that the segregation pattern of the afferents stays the same, albeit, with more labeled terminals, and more intense and brighter labeling after longer diffusion time. Yellow indicates overlap of the green and red fiber population along the z-axis. It also indicates presence of a double labeled fiber population, sending collaterals to both the cerebellum and vestibular nuclei. Scale bars $100 \mu \mathrm{m}$
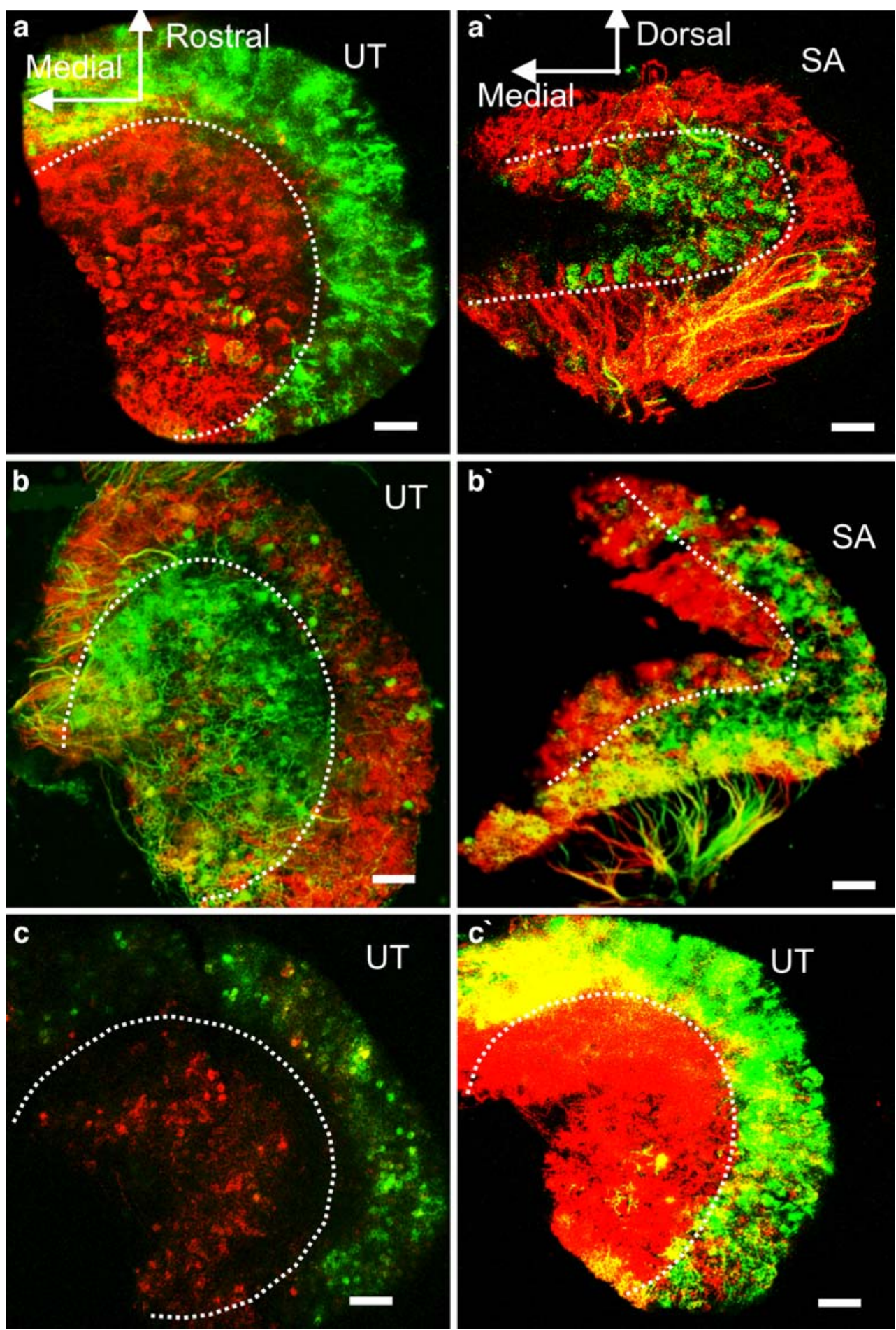

were examined after two diffusion time points; 3 weeks and 5 weeks. In this group, we observed that the peripheral distribution pattern of the cerebellar and brainstem afferents around the LPR did not change. However, we only observed an increase in the number of the labeled fibers and terminals and in the brightness of labeling without changing the general trend of distribution of the two populations (Fig. 2c, c').
Afferent fiber segregation at P0

\section{Cerebellar single tracer application}

At birth, DiI diffusion from implants into the uvula and nodulus of the cerebellum was present within all the examined peripheral endorgans as red fluorescent fibers (Fig. 3a-c). However, the labeled fibers did not distribute 
Fig. 3 Otolith endorgans of P0 pups are labeled by dye application to the cerebellum $(\mathbf{a}-\mathbf{c})$, and brainstem $\left(\mathbf{a}-\mathbf{c}^{\prime}\right)$. a Afferents in the utricular macula (UT), labeled from the cerebellum, show labeling almost exclusively lateral to the LPR (dotted line). Labeled fibers in the medial half are mostly fibers of passage, which disappear as we approach the terminals on hair cells. a' Afferents in the utricular macula $(U T)$, labeled from the brainstem, show that the primary vestibular afferents to the medulla and pons are derived mainly from an area medial to the LPR. The utricular macula lateral to the LPR is almost devoid of labeling except for efferent collaterals and a few afferent populations at the rostral and caudal poles (arrows). b Afferents in the saccular macula $(S A)$, labeled from the cerebellum, show that the primary vestibulocerebellar afferents are derived mainly medial to saccular LPR (dotted line). Labeled fibers on the other side of LPR are parent fibers of passage. b' Afferents in the saccular macula $(S A)$ show that the primary vestibular afferents to the medulla are derived mainly from an area lateral to the LPR. c Calyx and bouton endings in the utricular macula are labeled from the cerebellum. c' Calyces and boutons in the utricular macula are labeled from the brainstem. Scale bars $100 \mu \mathrm{m}$
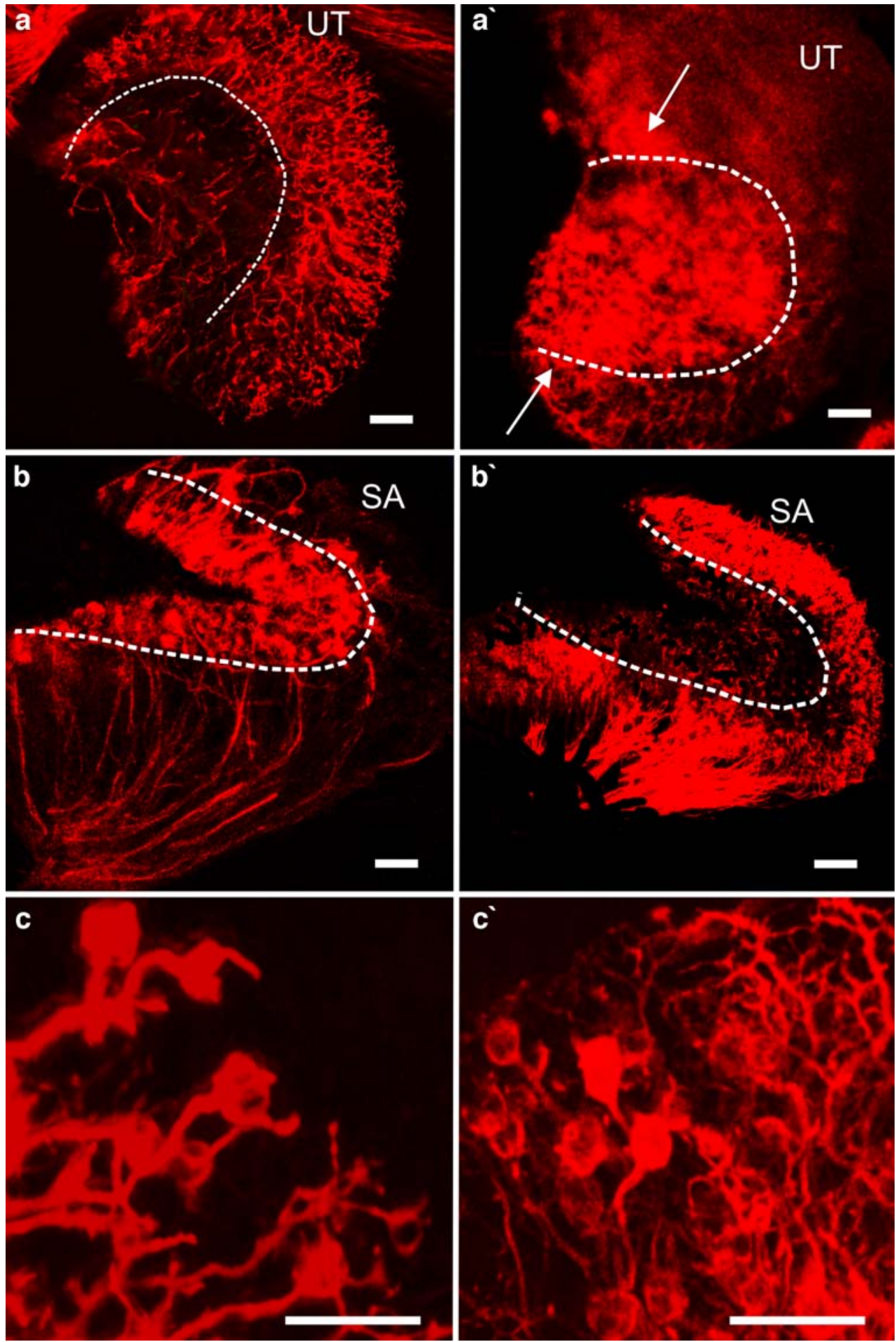

homogeneously throughout the vestibular epithelium. Instead, they showed a pattern of fiber segregation in the five vestibular endorgans examined.

In the otolith endorgans, the segregation pattern of the peripheral processes was striking. In the utricle, the peripheral arbors of the primary vestibulocerebellar projection formed a crescent shaped rim making up the lateral half of the utricular macula (UT) (Fig. 3a). The arbors forming the primary cerebellar projection from the utricular macula stopped abruptly at a curved line (Fig. 3a; dotted line) passing roughly in the middle of utricular macula. This line is consistent with the utricular LPR region in mice as described elsewhere (Mbiene et al. 1984; Desai et al. 2005; Li et al. 2008). Only a few large parent fibers of passage were observed on the other side of this border. Likewise, in the saccular macula (SA), DiI in the uvula and nodulus 
labeled afferent terminals in an area medial to saccular LPR (Fig. 3b; dotted line). Lateral to LPR, there were only primary axons of passage in their way to the medial extrastriolar region.

\section{Brainstem single tracer application}

In contrast to cerebellar application, DiI implantation in the brainstem labeled domains that mirrored the cerebellar domains in the otolith endorgans (Fig. 3a', b'). In the utricular macula (UT), labeled terminals were restricted to an area medial to the LPR (Fig. 3a'). Lateral to the LPR, very few afferent terminals clustered mainly in the rostral and caudal poles (Fig. 3a'; arrows) and fine efferent terminals were distributed throughout the lateral half.

In the saccular macula (SA), afferents labeled from the brainstem were confined to the one half lateral to the LPR (Fig. 3b'). Medial to it, there were numerous fine efferent terminals throughout the medial half of the saccular macula. In both utricular and saccular macula, both calyceal and bouton endings were labeled from both central targets (Fig. 3c, c'). However, due to the high density of labeling, it was difficult to distinguish the dimorphic endings from calyceal or bouton only endings.

\section{Two tracer applications}

To directly compare the peripheral domains of afferent projections to the brainstem and cerebellum in the same preparations we employed two tracers: DiI in the brainstem and Neuro Vue Maroon in the cerebellum.

In the utricular macula (UT), Neuro Vue Maroon in the cerebellum retrogradely labeled afferent fibers (green) lateral to the LPR, mostly filling the lateral half of the utricular macula, with very few terminals in the medial half (Fig. 4a). In contrast, DiI in the brainstem labeled afferent fibers (red) medial to the LPR mostly filling the medial half of the neuroepithelium. As in single application experiments, clusters of afferent endings were observed only in the rostral and caudal poles of the lateral half of the macula (Fig. 4a; arrows). Several efferent terminals were seen crossing the LPR to reach the lateral half of the maculae.

In the saccular macula (SA) (Fig. 4b), Neuro Vue Maroon insertion into the cerebellum labeled afferent fibers and terminals (green) medial to the saccular LPR, filling almost all medial half of the neuroepithelium (Fig. 4b) with very few terminals seen in the lateral half. DiI in the brainstem labeled afferent fibers and terminals (red) lateral to the LPR, almost filling the lateral half of the macula (Fig. 4b). In both utricular and saccular maculae, there were islands of yellow-colored terminals around the LPR. However, in wholemount preparations where several structures overlap, it is difficult to assess whether the yellow terminals are due to spatial overlap of the green and red labeled structures or terminals projecting branches to both central targets. Both the calyceal and bouton endings (Fig. 4c; arrows and arrowheads, respectively) were labeled in the utricular and saccular maculae from both the VCN and cerebellum (Fig.4c and d, respectively).

In the canal cristae (Fig. 4e, f), Neuro Vue Maroon in the cerebellum labeled afferent fibers (green) on both sides of the canals' cristae. However, there were more cerebellar afferents in the superior halves of the anterior (AC) and horizontal canal (HC) (Fig. 4e, f; arrows) than there were in the inferior halves (Fig. 4e, f; arrowheads). Afferent fibers retrogradely labeled from brainstems (red) were homogenously distributed between the superior and inferior halves of all canals' cristae (Fig. 4e, f). Yellow patches in the superior halves of the canal cristae were extensive. However, these patches were interrupted by green and red areas, indicating that the yellow staining is generated by the spatial overlap of green and red fibers populations. True double labeling will generate yellow color throughout the entire fiber trajectories.

\section{Afferent fiber segregation at $\mathrm{P} 7$}

At P7, double labeling of the primary vestibular afferent projections from the brainstem and cerebellum showed that there was clear segregation of the peripheral domains projecting to the VNC and cerebellum in all endorgans (Fig. 5).

In the otolith endorgans, double labeling obviously showed clear segregation of the primary vestibular projection to the VNC and cerebellum. In the utricular macula (UT), the fiber bundle containing the parent axons contained yellow and red regions. This yellow was produced by the overlap of green fibers projecting to the cerebellum and red fibers projecting to the vestibular nuclei, which were traveling together (Fig. 5a). Red regions presumably just contained fibers projecting to the vestibular nuclei. In contrast, at the level of the vestibular epithelium hair cells, the two sets of fluorescent fibers were sharply segregated into two domains (Fig. 5a). The crescent-shaped region lateral to the LPR (Fig. 5a) contained virtually all of the green arbors labeled from the cerebellum (green zone). This region also contained a small population in the caudal pole of the crescent that was labeled (red) from the vestibular nuclei injection (Fig. 5a). Medial to the LPR, nearly all the labeled arbors fluoresced red, indicating these fibers projected almost exclusively to the vestibular nuclei (red zone). Very few terminals were labeled green from the cerebellar injection. In the saccular macula (SA) (Fig. 5b), a V-shaped area medial to the saccular LPR was labeled almost exclusively from the cerebellar injection (green arbors), whereas the V-shaped domain lateral to it was 
Fig. 4 Distribution of the primary vestibular afferents projecting to the cerebellum (green) and brainstem (red) in the peripheral endorgans at $\mathrm{P} 0$. a A confocal image of utricular macula (UT) in which the afferents projecting to cerebellum are mainly located lateral to the LPR, whereas the brainstem afferents are mainly located medial to it. A few calyceal and bouton endings labeled from brainstem are observed in the rostral and caudal poles of the lateral region (arrows). b Saccular macula $(S A)$ in which the afferents projecting to cerebellum are located medial to the LPR, and brainstem afferents are located lateral to it. c A higher magnification image of the lateral extrastriolar region of utricular macula shows both the calyceal (arrows) and bouton (arrowheads) endings. The red, fine beaded fibers are efferents. d Calyces and boutons endings are shown in the medial extrastriolar region in the utricular macula. e,f Anterior $(A C)$ and horizontal $(H C)$ canals cristae, respectively. Note that the afferents projecting to cerebellum (green) are more in the superior halves (arrows) than in the inferior halves (arrowheads). Brainstem afferents (red) are homogenous in the hemicristae of all canals. Scale bars $100 \mu \mathrm{m}$
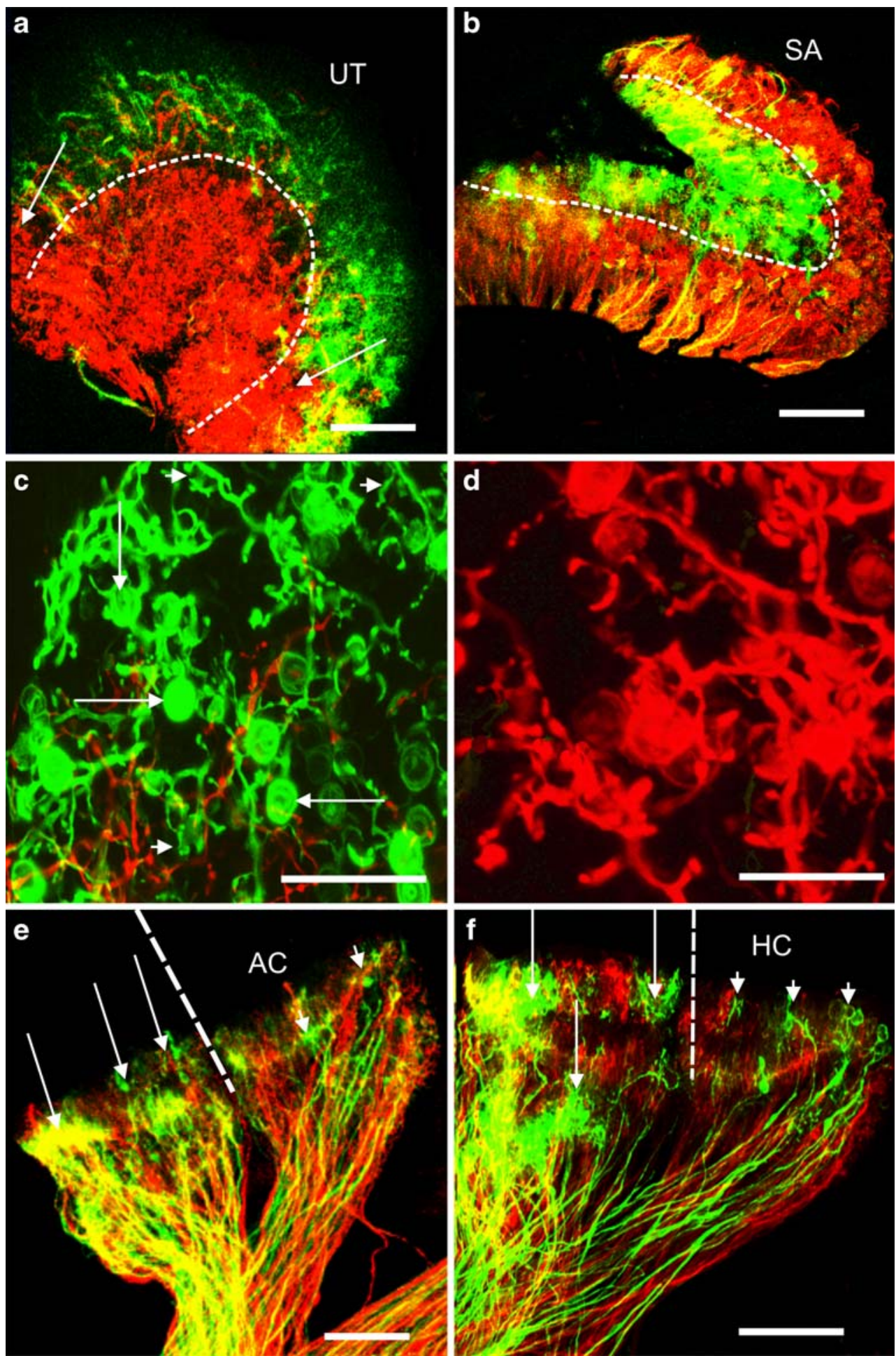

labeled almost exclusively from the VNC injection. There were also regions that fluoresced yellow. These regions contain overlapping labeled fibers and cannot be interpreted from this perspective.

Details of the arborization pattern can be seen in Fig. 5 (a', b'). In both the utricle (Fig. 5a') and saccule (Fig. 5b') it is clear that nearly all of the green fluorescing arbors from the cerebellar injection are located on one side of the presumed LPR, even if their parent fibers are sometimes observed on the other side of the line. Similarly, the vast majority of red fluorescing arbors labeled from the vestibular injection lay on the other side of the line. These higher magnification views also make it clear that the fields of fluorescent fibers observed at lower magnification are in 
Fig. 5 The distribution of primary vestibulocerebellar (green) and vestibulonuclear (red) fibers in the vestibular endorgans of P7 mouse in the double labeling experiment. a Macula of the utricle (UT) shows complete segregation of cerebellar projections (green) lateral to the LPR, and VNC projection (red) medial to it. a' A higher magnification view from (a) shows the afferents segregation line at the LPR, and the morphology of individual labeled arbors. The red terminals, lateral to the LPR, indicate mainly efferent terminals labeled from the $\mathrm{VNC}$, and a few outliers projecting to the VNC. $\mathbf{b}$ The saccular macula shows segregation of cerebellar fibers (green) medial to LPR and VCN fibers (red) lateral to it. b' A higher magnification view from (b) shows the segregation of cerebellar and brainstem afferents around LPR, and the details of afferent terminals. $\mathbf{c}$ The cristae of the $A C$ and $H C$ show a relatively equal distribution of the fibers labeled from the VNC (red) in the two halves of the cristae, whereas fibers labeled from the cerebellum (green) are more extensive in the superior halves of these end organs. Yellow, which indicates the apparent overlap of red and green fibers, is more obvious in the superior halves of these end organs. c' Crista of PC shows homogenous VNC projection (red) from the two halves, and more extensive cerebellar projection (green) from its superior half. Both calyx and bouton endings are labeled from both central targets. Scale bars $100 \mu \mathrm{m}$
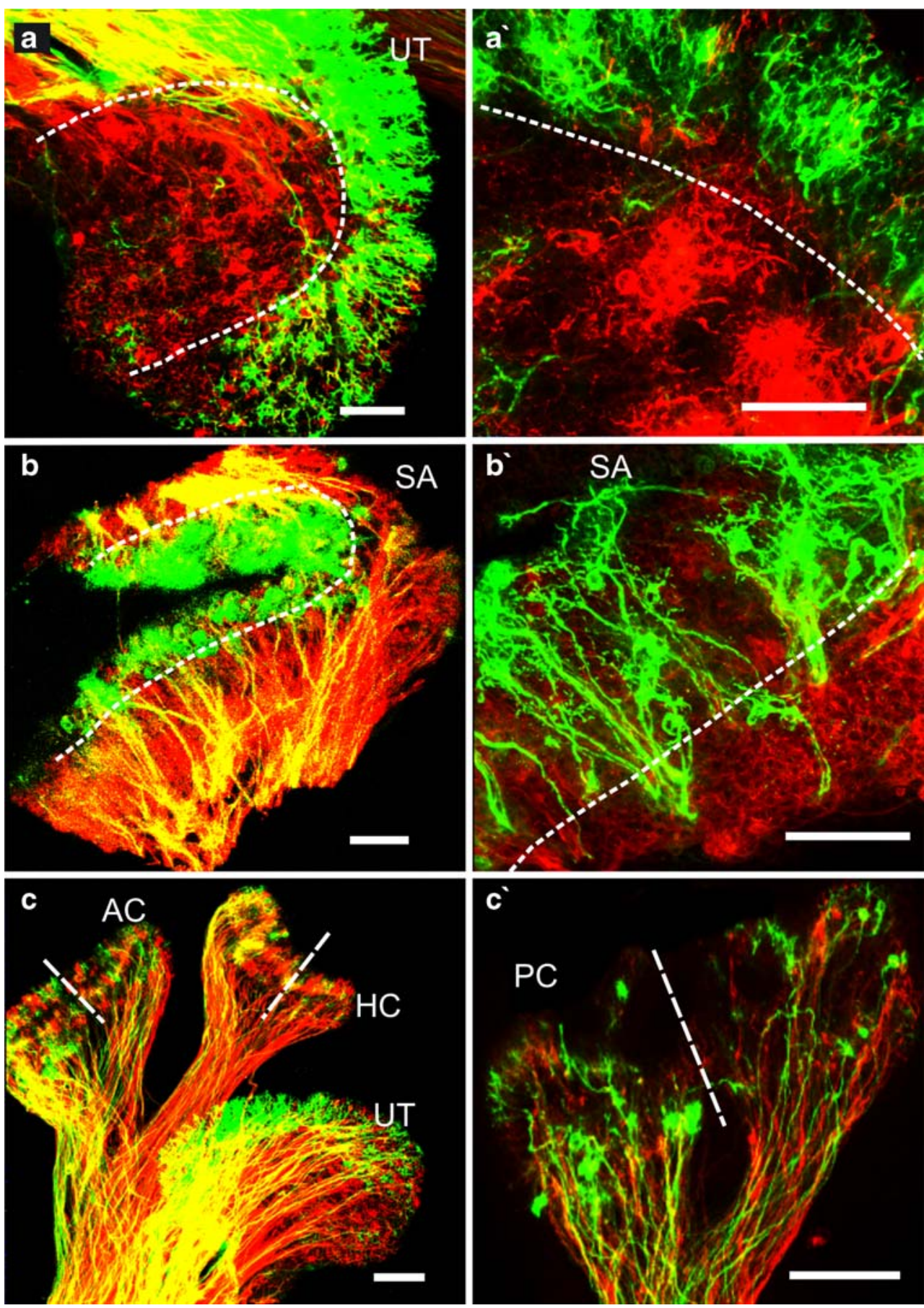

fact formed by the arborization of individual labeled axons as they extend up to contact the hair cells in the vestibular epithelium. Both calyceal and bouton endings were labeled from both implantation sites.

Following the dual tracer injections in the vestibular nuclei and cerebellum, the pattern of labeling present in the cristae was a complex one. The two populations formed a patchwork of labeled fibers in and beneath the vestibular epithelium, although the red fibers labeled from the VNC were the dominant component (Fig. 5c, c'). This pattern is shown at higher magnification (Fig. 5c'), which also demonstrates that both calyx and bouton type endings have been labeled by this approach. In most cases, only red or green arbors were observed, indicating uptake of dye from a single central structure, especially when the epithelium is examined under high power (Fig. 5c'). Only rarely were yellow arbors present, suggesting collaterals might be present that target both the cerebellum and VNC. In the anterior canal (AC), the primary vestibular fibers from injections in the VNC (red) were present in approximately 
equal numbers within the superior and inferior halves of the crista (Fig. 5c). In contrast, far more fibers labeled from the cerebellum (green) were present in the superior half of the crista compared to the inferior half (Fig. 5c). The horizontal canal (HC) reiterated this pattern of equal numbers of labeled fibers projecting from the superior and inferior halves of the crista to the VNC, while the larger projection to the cerebellum originates from the superior half of the end organ (Fig. 5c).

Similarly, the posterior canal (PC) showed equivalent levels of red fibers labeled from VNC injections within their superior and inferior halves. Once again, many more green labeled fibers, filled from cerebellar injections, were found in the medial half of the crista (Fig. 5c').

Development of the primary vestibular afferent segregation

\section{Afferent fiber segregation at E11.5}

Embryonic day E11.5 is around the earliest onset of vestibular neuron connection with the brainstem (Fritzsch 2003; Maklad and Fritzsch 2003a, b). This was therefore used to evaluate, with newly available multicolor lipophilic dye tracing (Jensen-Smith et al. 2007), the segregation of early fiber growth from the ear to the brain in unprecedented clarity. We previously showed that the vestibular afferents first reach the brain at E11.5, using small dye injections into the developing ear. Here, we show that large injections of three differently colored NeuroVue dyes into the cerebellum, caudal medulla, and rhombomere 4 (the origin of the facial branchial motoneurons and vestibular and cochlear efferents; Fritzsch and Nichols 1993) label only a few sensory neurons and efferent fibers to the developing ear (Fig. 6c, d). Most obvious is a clear segregation of sensory neurons in the inferior vestibular ganglion that projects to the posterior canal crista. Here, the nearby neurons are either labeled with one or the other color and show no colocalization of both colors (Fig. 6c, d). These data suggest that certain neurons project initially toward the cerebellum while others project initially to the caudal medulla. Consistent with this finding is the behavior of fibers backfilled from the injection sites near the VIIIth nerve root. If each fiber were to bifurcate, one would expect to see either projection to show significant extension and overlap with the other projection. In contrast, most fibers in a given labeled bundle terminate at the VIIIth nerve root and show only a few fibers that extend for a short distance rostral or caudal beyond the root (Fig. 6b).

These data indicate that postmitotic vestibular sensory neurons project initially either rostrally or caudally into the brain. There is at least a 1-day delay before many fibers develop branches that project in the initially non-preferred direction. This initial projection is consistent with data in lampreys that show either rostral or caudal projections of the canal cristae (Fritzsch 1998).

Afferent fibers segregations at E13.5, E14.5, E15.5, and E16.5

Embryonic ages (E13.5-E16.5) were employed to examine whether or not the initial fiber outgrowth undergoes pattern refinement during the rest of embryonic development. At E13.5, all five vestibular endorgans are fully formed, and hair cell polarity becomes established in mice (DenmanJohnson and Forge 1999). At this age, Neuro Vue dye implantation in the cerebellum and DiI in the brainstem labeled afferent fibers in all five vestibular endorgans (Fig. 7a). However, the cerebellar afferents showed a more restricted distribution in one half of all endorgans as revealed by yellow color of overlapping green and red (Fig. 7a). At E14.5 (Fig. 7b), further restriction in the distribution of the two afferent populations became apparent. In the otolith maculae, the two afferent populations had more restricted distribution relative to the presumptive LPR. In the canals, the cerebellar afferents became more restricted to the superior halves of the canal cristae (Fig. 7b).

At embryonic days E15.5 and E16.5, the afferent segregation pattern in the canal remained the same with more cerebellar afferents in the superior halves of the canals'cristae (Fig. 7c and d, respectively) as in the previous embryonic ages. In the utricular and saccular maculae, progressive restriction of the overlap between the cerebellar (green) and brainstem (red) afferent populations occurred as revealed by the decrease of the yellow color where the two populations overlap (Fig. 7c, d). At these later embryonic ages, a more adult-like segregation pattern around the LPR became established. Examination of vestibular ganglia at these ages revealed that cell populations projecting to the brainstem or cerebellum were distinct and resided in topographically distinct loci. Yellow-labeled loci were mostly observed in the equatorial region of the superior vestibular ganglion (Fig. 7e). This region is the thickest region of the ganglion, in which the spatial overlap of a large population is maximal. However, single optical scan of this area at higher magnification revealed either red or green cells (Fig. 7f)

\section{Afferent fiber segregation at postnatal day 21 (P21)}

We chose to further investigate postnatal day 21 (P21) to ensure that the pattern obtained at the first postnatal week was fixed and continues through the times of late postnatal activity (de Caprona et al. 2004), and is likely permanent. 
Fig. 6 The fiber growth to the ear in E11.5-day embryos. The injection of three different dyes into the cerebellum $(C B)$, red in $(\mathbf{a}, \mathbf{b})$, the brainstem green in $(\mathbf{a}$, b) and into rhombomere $4(r 4)$ efferents, blue in $(\mathbf{a}, \mathbf{b})$ reveals a non-overlapping projection to the ear $(\mathbf{c}, \mathbf{d})$. Cerebellar afferents to the posterior canal (red in c,d) and brainstem afferents to the posterior canal (green in c,d) are each singly labeled with either color. Likewise, efferents are discreetly labeled (blue in $\mathbf{c}$, d). Consistent with the peripheral labeling, central projections show only few green brainstem fibers to extend beyond the VIIIth nerve root (arrow in b) and only an occasional red cerebellar fiber projects into the brainstem. Combined, these data suggest that the initial fiber growth from sensory neurons to the brain is biased into a population that projects primarily to the brainstem and a population that projects primarily to the cerebellum. Scale bars $100 \mu \mathrm{m}$
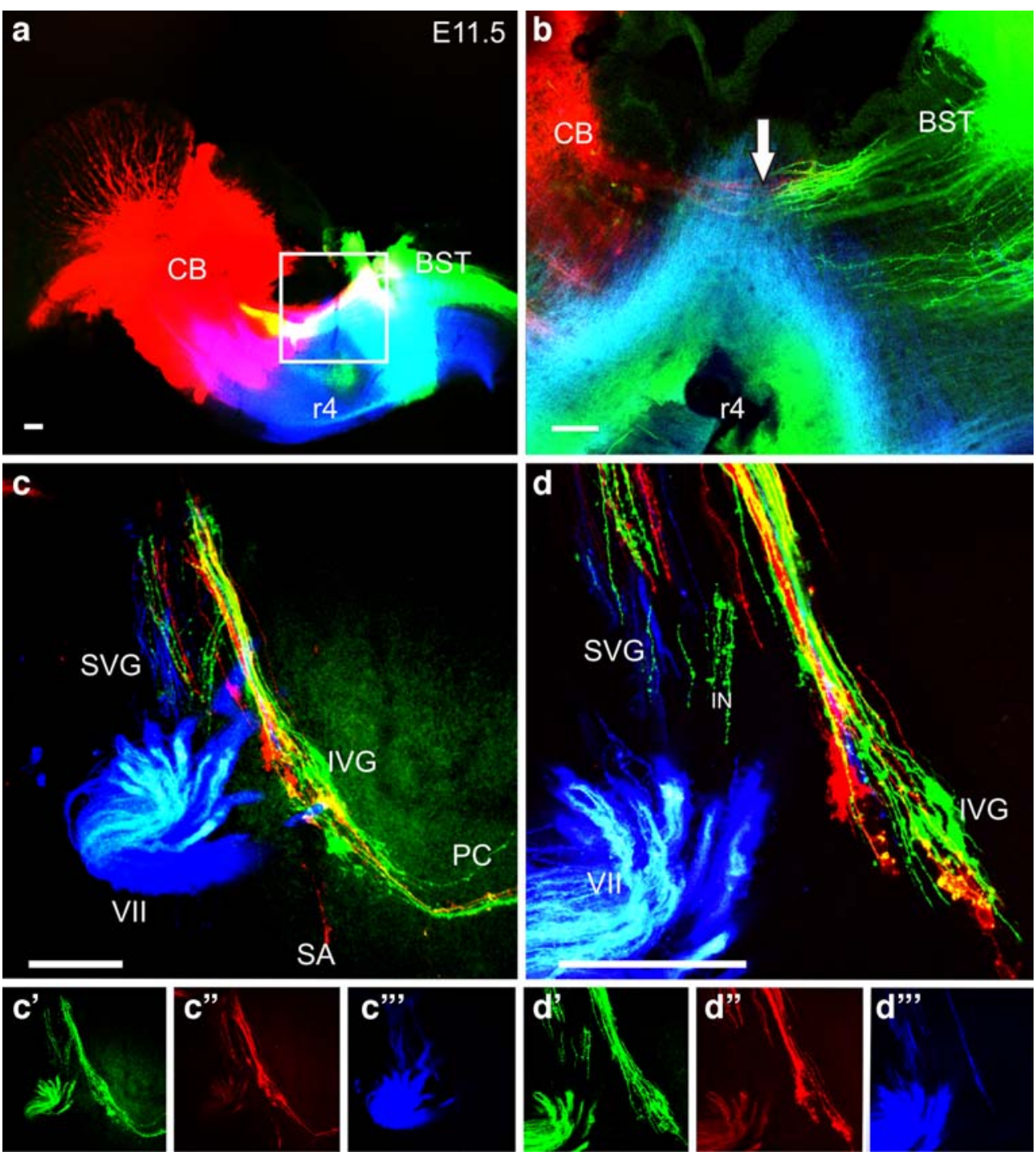

At P21, the afferent segregation pattern obtained at P0 and P7 persisted in all endorgans. In the utricular macula, the cerebellar afferents (green) were mainly lateral to the utricular LPR (Fig. 8a). The lateral region appeared exclusive for cerebellar afferents, as limited population of red terminals or yellow fibers appeared as fine terminals consistent with efferent fibers anterogradely labeled from the brainstem. The brainstem afferents (red) were mainly localized in the medial region (Fig. 8a). Numerous yellow fibers and hair cells were observed in this area. At these ages, examination of the saccular maculae revealed afferent segregation pattern around the saccular LPR similar to that obtained at earlier time points (Fig. 7b). In the canal cristae, there were more cerebellar afferents (green) in the superior half (Fig. 8c) than there were in the inferior half (Fig. 8d). Brainstem afferents were equally distributed on either side of the cruciate eminence (Fig. 8c, d). As in younger ages, calyceal and bouton endings were labeled in all endorgans from both central targets (Fig. 8c,d,e).
Fig. 7 Vestibular afferents segregation as it appears between E13.5E16.5. a Cerebellar and brainstem afferents are shown at E13.5. Note that the cerebellar afferents colocalize with brainstem afferents (as indicated by yellow color) mainly in the superior side of the canal cristae, and lateral to the LPR (dotted line) in the utricular macula, and medial to it in the saccular macula. b Cerebellar and brainstem afferents segregation is shown at E14.5. At this age, the cerebellar fibers are now more restricted to one side in the canal cristae and to one side of the striola in gravistatic organs. c,d Vestibular afferents segregation at E15.5 and E16.5, respectively. Note that the brainstem and cerebellar afferents segregation becomes more pronounced in the superior halves of all canal cristae. In the utricular and saccular maculae, the cerebellar fibers (green) become progressively localized to one side of the presumptive LPRs (dotted lines) while the brainstem fibers (red) become distributed to the other side. Note also that the overlap (yellow) between the two domains is now minimal, showing an adult-like pattern reported from $\mathrm{P} 0$ on. e Vestibular ganglion shows the green cells (labeled from the cerebellum) and red cells (labeled from the brainstem) as distinct populations. The extensive yellow stain in the central region is generated by the overlap of green and red cells when the z-stack of images of the whole-mount ganglion is collapsed. f A single scan of higher magnification of the frame in (e) shows that the green and red cells are clearly distinct, and yellow staining is now minimal. Scale bars $100 \mu \mathrm{m}$ 

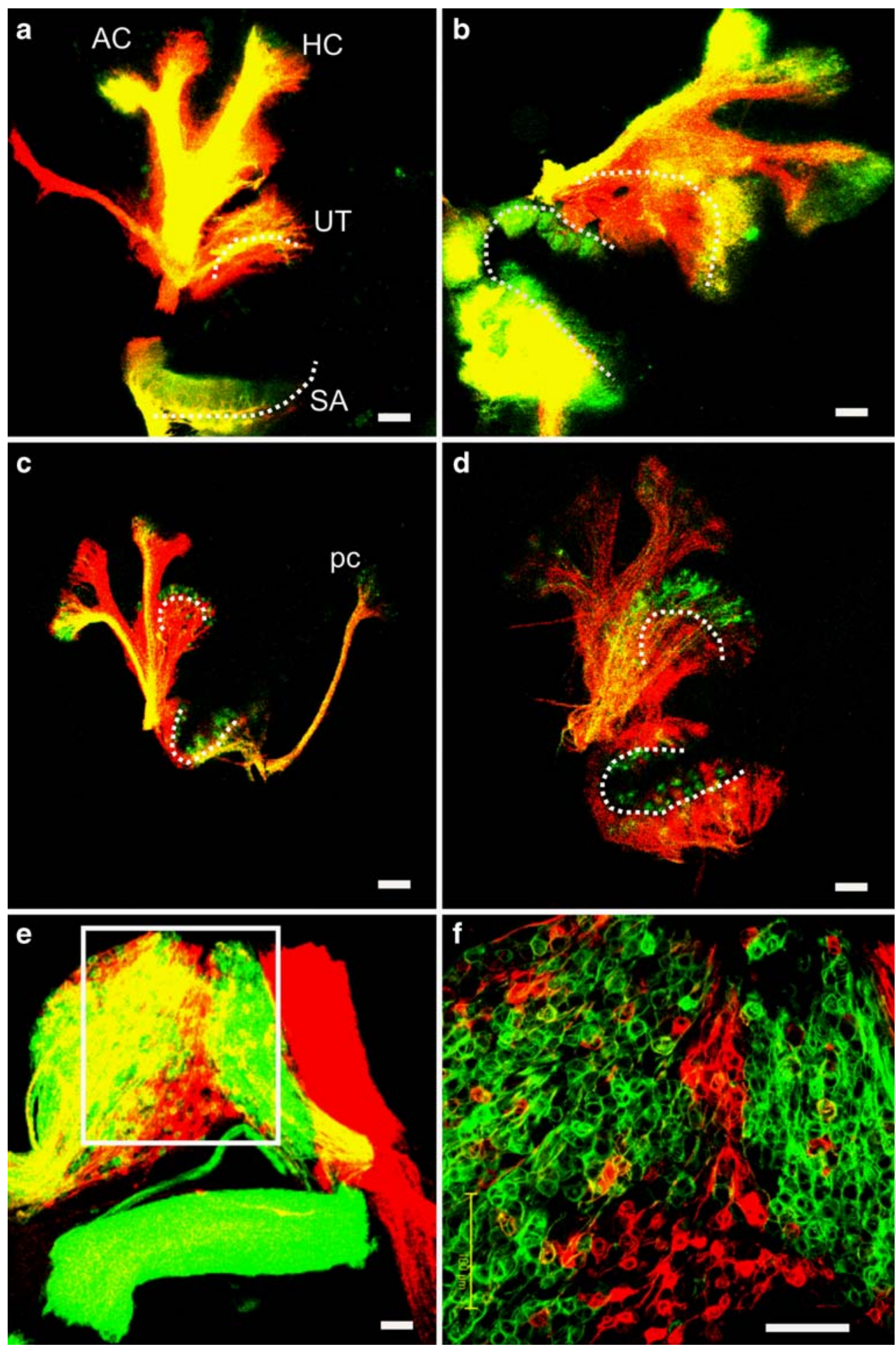

Examination of the vestibular ganglia at this age revealed that the vestibular ganglion cells projecting to either the brainstem or cerebellum are distinct, as revealed by their respective red or green colors in single optical confocal sections. Some cells appeared partially yellow in projections of multiple optical sections into a single plane, suggesting z-axis spatial overlap of two adjacent green and red cells but not co-labeling. Indeed, fewer cells appeared yellow in single optical planes, suggesting that the true double labeled cells (Fig. 8f) are as rare as outliers of the afferent terminals in the utricular and saccular sensory epithelia. 
Fig. 8 Vestibular afferents are still segregated at P21. a The cerebellar and brainstem afferents segregation around the LPR in the utricular macula is similar to earlier time points. b Saccular macula of the same age shows afferent distribution around the saccular LPR (dotted line) similar to those described in younger age groups. $\mathbf{c}, \mathbf{d}$ Superior and inferior halves of the horizontal canal show more cerebellar fibers (green) in the superior half (c) than those in the inferior half (d). Brainstem fibers (red) were homogenously distributed between the two hemicristae. e A utricular macula shows that calyx and bouton endings are labeled from VNC and cerebellum. f The vestibular ganglion cells projecting to the cerebellum (green), and those projecting to the brainstem (red) are distinct populations. Note that a few cells are labeled yellow. These cells send collaterals to both the cerebellum and brainstem, and therefore are double labeled. Scale bars $100 \mu \mathrm{m}$
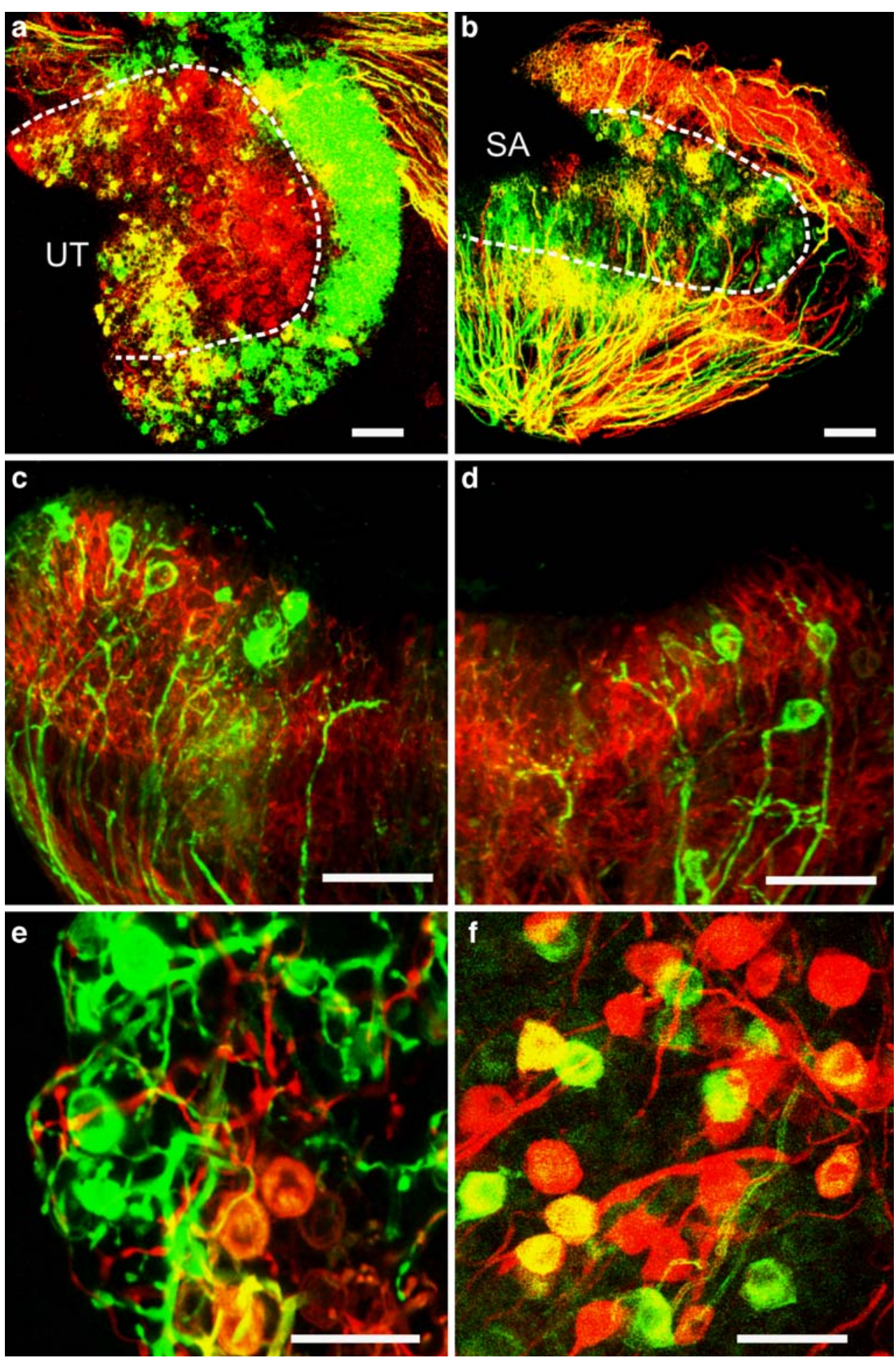

\section{Discussion}

The present study was undertaken to delineate the initial growth pattern of vestibular axons and to investigate the polarity-specific segregation of the vestibular endorgans projections to the brainstem and cerebellum. Our data reveal a novel trend of rostral and caudal (but less bifurcating) initial projections and a segregation of cerebellar and brainstem afferents along the presumed striolar line. Thus, this segregation of the primary vestibular afferents with respect to CNS targets conforms to the known polarity difference of the hair cells on the two sides of the striola in otolith maculae (Lindeman 1969; Wersäll et al. 1965; Lewis et al. 1985). Specifically, hair cells found lateral to the line of polarity 
reversal (LPR) in the utricular macula, and medial to it in the saccular macula are apparently supplied by afferents that project almost exclusively to the cerebellum. In contrast, hair cells found medial to the LPR in the utricular macula and lateral to it in the saccular macula are supplied by afferents that project to the brainstem VNC. A few outliers existed on either side. The segregation across that line was so clear that we will refer to one side of the macula as the "cerebellar macula" and the other side as the "vestibular nuclear macula" in this discussion. A non-homogeneous distribution of primary afferents supplying the cerebellum was not only present in the macula, but also in the canal cristae. However, the crista showed only a partial segregation in which the superior halves of all canal cristae have a heavier projection to the cerebellum than do inferior halves. In addition, the fibers targeting the $\mathrm{VNC}$ and cerebellum formed a patchwork pattern within the vestibular epithelium.

Developmental implications of the anatomical segregation

Our data reveal an interesting pattern of segregation of the primary vestibulocerebellar fibers in all endorgans and this segregation is apparently related to initial pathway choices to project either to the cerebellum or the brainstem (Fig. 6). This suggests that positional information laid down along the mediolateral or dorsoventral axes of vestibular endorgans could be read differently by the primary vestibular afferents to the cerebellum and medulla. The segregation of the central projections of the primary afferents to the $\mathrm{VNC}$ and cerebellum at the presumed polarity reversal line suggests that cues related to hair cell polarity differences can also provide differential guidance cues for afferents.

In the utricular macula, the primary afferents projecting to the cerebellum originate lateral to the LPR in the utricle and medial to it in the saccule. In mice, there are slight inclinations in the utricular and saccular maculae in such a way that the lateral extrastriola in the utricle and medial extrastriola in the saccule, the cerebellar hemimaculae, are at more dorsal levels than the nuclear hemimaculae. The dorsal locations of the cerebellar afferent domains in all endorgans suggest that the global polarity of the vestibular apparatus might be the overriding factor in providing positional information or that the gradients guiding the development of this process may be set up across the entire structure (Barald and Kelley 2004; Jones and Chen 2007). It is likely that a gradient laid down along the dorsoventral axis of the hindbrain and the adjacent otocysts align the afferent domains with their central targets' structure. Given the targeted growth of afferents, even in the absence of hair cell formation (Fritzsch et al. 2005a; Matei et al. 2005), it is likely that afferents are molecularly specified to respond to polarity cues much like hair cells and thus sort each other out along common parameters.
It should be noted that the segregation pattern starts at the outset (embryonic day 11.5) with minor refinement of the projection over the next few embryonic days (E12.5E15.5) to become adult-like at E16.5. These events are in place long before the granule cells become postmitotic and migrate to their final destination and prior to onset of significant vestibular function (de Caprona et al. 2004). Since a functional internal granular layer is not present until near the end of the first postnatal week (Fujita et al. 1966; Altman and Bayer 1985; Morin et al. 2001), it seems unlikely that contact with the cerebellar granule cells guides the formation of a segregated peripheral pattern. This fact is supported by the extremely early development of directional ingrowth of afferents to the cerebellum and brainstem, respectively.

Comparison to previous studies

The present study is the first report to examine the central projection of the primary vestibular afferent at such early stages, and with respect to the polarity reversal at the striola in otolith organs. Our data demonstrate a novel finding that the primary otolith afferents to the brainstem and cerebellum are peripherally segregated at the LPR; that is, the otolith afferents from one side along that line project mainly to the cerebellum, whereas the afferents from the other side project mainly to the brainstem. This pattern correlates with the known hair cell polarity reversal within the striola region (Lewis et al. 1985). Purcell and Perachio (2001) were the first to attempt mapping the peripheral domains projecting to the cerebellum. They reported that the majority of afferent terminals were of dimorphic type and located in the peristriola region in the otolith organs, with sparse labeling in the medial and lateral extrastriola. This implies that the majority of afferents in the medial and lateral extrastriolar regions presumably project to vestibular nuclei. This finding is not in accord with ours. Our data suggest that the lateral extrastriolar region in the utricle and medial extrastriolar region in the saccule are almost exclusive for cerebellar afferents. Such conflict may have stemmed from the constraints of the surgical approach and very discrete injections $(50-250 \mu \mathrm{m})$, resulting in partial labeling of the cerebellar afferent population. Our use of postfixation retrograde transport along with mid-sagittal cut of the brain have offered us, with a relative ease, a wide open access to the brainstem and cerebellar vermis, with consequent labeling of almost the entire cerebellar and nuclear afferent populations.

The central vestibular projections have been thoroughly analyzed at different levels over the past century. Once the central projections of the vestibular nerve were identified (Cajal 1896; Brodal and Høivik 1964; Korte and Mugnaini 1979; Carleton and Carpenter 1984), a determination of the 
endorgan-specific projections in several vertebrate taxa was possible (Lorente de No 1933; Schwarz and Schwarz 1986; Naito et al. 1995; Maklad and Fritzsch 2002; Newlands et al. 2002; Kevetter et al. 2004; see Newlands and Perachio 2003 for review).

Other studies have attempted to establish functional and morphological localizations of different classes of the afferent fibers in the sensory epithelia. These studies have demonstrated that different physiological and morphological classes of fibers distribute themselves to discrete areas in the sensory epithelia of all endorgans in several vertebrate taxa (Baird et al. 1988; Fernández et al. 1988, 1990; Goldberg et al. 1990; Baird and Schuff 1994; Lysakowski et al. 1995; Si et al. 2003; Zakir et al. 2003; Haque et al. 2006). Interestingly, the localization of different classes of afferents follows an inside-out organization, from the striola to the periphery, in the saccular and utricular maculae (Fernández et al. 1990; Goldberg et al. 1990; Baird and Schuff 1994; Si et al. 2003; Zakir et al. 2003). Such morphophysiological segregation of afferents is largely maintained centrally, although convergence also occurs (Goldberg et al. 1990; Highstein et al. 1987; Dickman and Fang 1996), and is restored after regeneration of hair cells in chicken (Zakir and Dickman 2006). The afferent segregation reported in our study does not conform with this functionally or morphologically-based macular localization. The otolith afferent segregation in our report conforms to the line of polarity reversal at the striola. Consequently, otolith information conveyed to either the brainstem or cerebellum must contain representatives of different physiological and morphological classes of afferent fibers and carry information processed by both types of hair cell.

In the canal's cristae, previous studies reported that different classes of afferents are topographically organized in three concentric zones based on their morphophysiologic characteristics (Baird et al. 1988; Fernández et al. 1988, 1995; Lysakowski et al. 1995; Haque et al. 2006): a scheme generally similar to that in otolith maculae. Furthermore, Purcell and Perachio (2001) suggested that cerebellar afferents preferentially derive from peripheral zones of the crista. In contrast, our data reveal a clear bias in the source of canal afferent fibers to the cerebellum, such that most originate from the superior hemicrista. Since hair cells in the two hemicristae of a given canal have uniform polarity, this finding is hard to explain as a polarity-based distribution pattern. However this may, in turn, imply that differential activation or recruitment of the hair cells in a canal crista occurs along the segregation axis (Rabbitt et al. 2001) even though they have a uniform polarity. This would require that the information from each hemicrista to be handled differently through specific central connections. It is also possible that the differential distribution of the cerebellar afferent between the canals hemicristae may be an evolutionary atavism reflecting a different polarity organization in ancestral ears.

Implications of the yellow labeling

In our study, we often observed yellow-labeled terminals and yellow-labeled vestibular ganglion cells. One possibility for the yellow labeling in the periphery is the local spread and central mixing of the tracers between the brainstem and cerebellum. However, our implementation of the appropriate controls eliminates this possibility. In our approach, we routinely performed a confocal z-series of several optical sections for a wholemount preparation. This Z-series of images was collapsed into a single 2D-image to be able to visualize all fiber populations throughout the entire structure. The collapse of a stack of images superimposes red and green fiber populations which are only segregated along the $\mathrm{z}$-axis, but not the $\mathrm{x} / \mathrm{y}$-axes, generating a yellow artifact when the red and green channels are merged. This yellow artifact accounts for the major part of the yellow staining in our preparations. The remaining part of the yellow population could possibly be true double labeled afferent population: a population that branches, sending collaterals to both the VNC and cerebellum. Studies using intracellular HRP injection into physiologically characterized primary vestibular otolith neurons suggest the existence of primary afferents which send collaterals to both brainstem and cerebellum (Sato et al. 1989; Imagawa et al. 1998; Newlands et al. 2002, 2003). Our data do not rule out these earlier observations, as afferent segregation in our study was not absolute. A few outliers existed around the LPR and the yellow-labeled fibers observed in our preparations may indicate the presence of fibers sending collaterals to both the brainstem and cerebellum. However, these populations are much less than previously reported (Barmack et al. 1993).

\section{Physiological considerations}

The clear segregation reported here for the otolith organs implies that the outputs from the hair cells of opposing polarities are almost completely segregated with respect to their central targets. Therefore, at least at the first synapse, these outputs do not anatomically converge onto the same neurons in the VCN in mice. This implies that, with a given natural stimulus, when the activity arising from the "nuclear macula" is facilitated, the activity arising from the "cerebellar macula" will be disfacilitated. The latter would result in a decrease in the rate of firing of the mossy fiber input to the granule cells and unipolar brush cells within the cerebellar cortex of the uvula and nodulus, decreasing their 
drive on Purkinje cells. Consequently, the Purkinje cell inhibitory influence over secondary vestibular neurons $\left(2^{\circ} \mathrm{VNs}\right)$ in VCN will be decreased. Thus, the disinhibitory input of the "cerebellar macula" is positioned to polysynaptically converge with the facilitated excitatory input from the "vestibular nuclear macula" on $2^{\circ} \mathrm{VN}$, producing a vectorially uniform effect. Such a tuning effect could increase the sensitivity of the otolith endorgans to natural stimuli. However, it should be noted that the cerebellar uvula and nodulus receives three different types of vestibular inputs: vestibular climbing fibers inputs from the contralateral inferior olive (Barmack and Shojaku 1995), and the primary and secondary vestibular mossy fiber inputs (Brodal and Høivik 1964; Korte and Mugnaini 1979; Carleton and Carpenter 1984; Epema et al. 1985; Newlands et al. 2002; Maklad and Fritzsch 2003a). They integrate information from these three sources and project back to VCN (Chan-Palay et al. 1979; Epema et al. 1985; Shojaku et al. 1987; de Zeeuw and Berrebi 1996; Wylie et al. 1999) to regulate spatial orientation, spatial memory, and reflexive eye movements (Ito et al. 1970, 1971; Angelaki and Hess 1995; Barmack et al. 2002; Cohen et al. 2002). Our findings suggest that the primary afferent input is oppositely tuned from secondary vestibular mossy fibers inputs, but it is not clear how these oppositely tuned inputs are integrated in the vestibulocerebellum. It is possible that the primary otolith information to the vestibulocerebellum is employed in feedforward circuits via granule, unipolar brush/Purkinje cell interaction (Mugnaini and Floris 1994; Dino et al. 2000) in order to unify or synergize different signals in the vestibular nuclei. However, such speculation needs further testing.

In cats, there is evidence that macular afferents from one side of the striolia project di-synaptically, via inhibitory interneurons, to $2^{\circ} \mathrm{VNs}$ in VNC (Uchino et al. 1997, 1999). These authors proposed a brainstem side-loop, which produces "cross-striolar inhibition" that presumably functions to increase the sensitivity of the otolith system. In the cat preparation, it was not possible to detect the existence of a cerebellar side-loop that may function in a similar fashion, due to removal of the cerebellum in the surgical approach to the VNC. Our data in mice suggest the existence of a second cerebellar side-loop that may provide a collateral channel for enhancing the sensitivity and plasticity of the otolith system.

The vestibular system and the mechanosensory cell is phylogenetically one of the oldest vertebrate sensory systems (Fritzsch et al. 2007). It shows a high degree of conservation at different morphological and physiological levels, as well as genetic developmental programming. However, canal cristae show significant differences: circular in hagfish, tripartite in lampreys, and mostly bipartite in jawed vertebrates (Fritzsch et al. 2002). How the ancestral vertebrate cristae were organized and how they projected remains unclear as no detailed projection analysis exists for hagfish and lampreys. In addition, hagfish have no cerebellum and the lamprey cerebellum is rudimentary with the trochlear motoneurons making up the largest contingent of what has been considered by some to be Purkinje cell precursors (Fritzsch et al. 1990). Importantly, most hair cell systems, including lateral line organs, are organized into opposing polarities of hair cells (Fritzsch 1981), leaving canal cristae as unique uniformly polarized epithelia. Whether canal cristae were ever organized into opposing polarities of hair cells, and lost this organization secondarily, remains unclear at the moment. It is likely that the mode of neuroanatomic circuitry revealed in mice may reflect a common mode of operation in jawed vertebrates. Thus, the possibility that the cerebellum evolved in ancestral jawed vertebrates to act as a collateral channel for sensory information processing in order to increase sensitivity, and fine-tune spatial information before transforming it into motor commands, is an appealing hypothesis. We are currently examining the conservation of this connectivity pattern in other vertebrate classes.

Acknowledgements We wish to thank Drs. Paul J. May, Duane Haines, Kimberly Simpson, and Richard Hallworth for their cogent suggestions on earlier drafts of this manuscript. We also wish to thank Dr. Heather Drummond for the use of the confocal microscopy facility and the Carver Trust and the University of Iowa for the purchase of the Leica SPE confocal microscope. We would like also to thank Dr. Marianne Conway, Mrs. Jennifer Kersigo, and Mr. Cole Hodges for streamlining the English in this version of the manuscript.

\section{References}

Altman J, Bayer SA (1985) Embryonic development of the rat cerebellum. I. Delineation of the cerebellar primordium and early cell movements. J Comp Neurol 231:1-26

Angelaki DE, Hess BJM (1995) Lesion of the nodulus and ventral uvula abolish steady-state off-vertical axis otolith response. J Neurophysiol 73:1716-1720

Baird RA, Schuff NR (1994) Peripheral innervation patterns of vestibular nerve afferents in the bullfrog utriculus. J Comp Neurol 342:279-298

Baird RA, Desmadryl G, Fernández C, Goldberg JM (1988) The vestibular nerve of the chinchilla. II. Relation between afferent response properties and peripheral innervation patterns in the semicircular canals. J Neurophysiol 60:182-203

Barald KF, Kelley MW (2004) From placode to polarization: new tunes in inner ear development. Development 131:4119-4130

Barmack NH, Shojaku H (1995) Vestibular and visual climbing fiber signals evoked in the uvula-nodulus of the rabbit cerebellum by natural stimulation. J Neurophysiol 74:2573-2589

Barmack NH, Baughman RW, Errico P, Shojaku H (1993) Vestibular primary afferent projection to the cerebellum of the rabbit. $\mathrm{J}$ Comp Neurol 327:521-534

Barmack NH, Errico P, Ferraresi A, Fushiki H, Pettorossi VE, Yakhnista V (2002) Cerebellar nodulectomy impairs spatial memory of vestibular and optokinetic stimulation in rabbits. $\mathrm{J}$ Neurophysiol 87:962-975 
Brodal A, Høivik B (1964) Site and mode of termination of primary vestibulocerebellar fibers in the cat. Arch Ital Biol 102:1-21

Büttner-Ennever JA (1999) A review of otolith pathways to brainstem and cerebellum. Ann N Y Acad Sci 871:51-64

Cajal SR (1896) Beiträge Zum Studium der Medulla oblongata, des Kleinhirns und des Ursprungs der Gehirnnerven. Barth, Leipzig

Carleton SC, Carpenter MB (1984) Distribution of primary vestibular fibers in the brainstem and cerebellum of the monkey. Brain Res 294:281-298

Carpenter MB, Stein BM, Peter P (1972) Primary vestibulocerebellar fibers in the monkey: distribution of fibers arising from distinctive cell groups of the vestibular ganglia. Am J Anat 135:221-249

Chan-Palay V, Palay SL, Wu JY (1979) Gamma-aminobutyric acid pathways in the cerebellum studied by retrograde and anterograde transport of glutamic acid decarboxylase antibody after in vivo injections. Anat Embryol 157:1-14

Cohen B, John P, Yakushin SB, Büttner-Ennever J, Raphan T (2002) The nodulus and uvula: source of cerebellar control of spatial orientation of the angular vestibulo-ocular reflex. Ann N Y Acad Sci 978:28-45

de Caprona MD, Beisel KW, Nichols DH, Fritzsch B (2004) Partial behavioral compensation is revealed in balance tasked mutant mice lacking otoconia. Brain Res Bull 64:289-301

Denman-Johnson K, Forge A (1999) Establishment of hair bundle polarity and orientation in the developing vestibular system of the mouse. J Neurocytol 28:821-835

Desai SS, Zeh C, Lysakowski L (2005) Comparative morphology of rodent vestibular periphery. I. Saccular and utricular maculae. J Neurophysiol 93:251-266

de Zeeuw CI, Berrebi AS (1996) Individual Purkinje cell axons terminate on both inhibitory and excitatory neurons in the cerebellar and vestibular nuclei. Ann N Y Acad Sci 781:607-610

Dickman JD, Fang Q (1996) Differential central projections of vestibular afferents in pigeons. J Comp Neurol 367:110-131

Dino MR, Nunzi MG, Anelli R, Mugnaini E (2000) Unipolar brush cells of the vestibulocerebellum: afferents and targets. Prog Brain Res 124:123-137

Epema AH, Guldemond JM, Voogd J (1985) Reciprocal connections between the caudal vermis and the vestibular nuclei in the rabbit. Neurosci Lett 57:273-278

Fernández C, Baird RA, Goldberg JM (1988) The vestibular nerve of the chinchilla. I. Peripheral innervation patterns in the horizontal and superior semicircular canals. J Neurophysiol 60:167-181

Fernández C, Goldberg JM, Baird RA (1990) The vestibular nerve of the chinchilla. III. Peripheral innervation patterns in the utricular macula. J Neurophysiol 63:767-780

Fernández C, Lysakowski A, Goldberg JM (1995) Hair-cell counts and afferent innervation patterns in the cristae ampullares of the squirrel monkey with a comparison to the chinchilla. J Neurophysiol 73:1253-1269

Flock A (1964) Structure of the macula utriculi with special reference to directional interplay of sensory responses as revealed by morphological polarization. J Cell Biol 22:413-431

Fritzsch B (1981) Electroreceptors and direction specific arrangement in the lateral-line system of salamanders. Z Naturforsch 36c:493-495

Fritzsch B (1998) Evolution of the vestibulo-ocular system. Otolaryngol Head Neck Surg 119:182-192

Fritzsch B (2003) Development of inner ear afferent connections: forming primary neurons and connecting them to the developing sensory epithelia. Brain Res Bull 60:423-433

Fritzsch B, Nichols DH (1993) DiI reveals a prenatal arrival of efferents at the differentiating otocyst of mice. Hear Res 65:51-60

Fritzsch B, Sonntag R, Dubuc R, Ohta H, Grillner S (1990) Organization of the six motor nuclei innervating the ocular muscles in lamprey. J Comp Neurol 294:491-506
Fritzsch B, Beisel KW, Jones K, Fariñas I, Maklad A, Lee J, Reichardt LF (2002) Development and evolution of inner ear sensory epithelia and their innervation. J Neurobiology 53:143-156

Fritzsch B, Matei VA, Nichols DH, Bermingham N, Jones K, Beisel KW, Wang VY (2005a) Atoh1 null mice show directed afferent fiber growth to undifferentiated ear sensory epithelia followed by incomplete fiber retention. Dev Dyn 233:570-583

Fritzsch B, Muirhead KA, Feng F, Gray BD, Ohlsson-Wilhelm BM (2005b) Diffusion and imaging properties of three new lipophilic tracers, NeuroVue Maroon, NeuroVue Red and NeuroVue Green and their use for double and triple labeling of neuronal profile. Brain Res Bull 66:249-258

Fritzsch B, Beisel KW, Pauley S, Soukup G (2007) Molecular evolution of the vertebrate mechanosensory cell and ear. Int $\mathrm{J}$ Dev Biol 51:663-678

Fujita S, Shimada M, Nakamura T (1966) H3-thymidine autoradiographic studies on the cell proliferation and differentiation in the external and the internal granular layers of the mouse cerebellum. J Comp Neurol 128:191-208

Goldberg JM (1981) Peripheral vestibular receptors: functional aspects. Am J Otol 3:68-79

Goldberg JM, Desmadryl G, Baird RA, Fernández C (1990) The vestibular nerve of the chinchilla. V. Relation between afferent discharge properties and peripheral innervation patterns in the utricular macula. J Neurophysiol 63:791-804

Haque A, Huss D, Dickman JD (2006) Afferent innervation patterns of the pigeon horizontal crista ampullaris. J Neurophysiol 96:3293-3304

Highstein SM, Goldberg JM, Moschovakis AK, Fernandez C (1987) Inputs from regularly and irregularly discharging vestibular nerve afferents to secondary neurons in the vestibular nuclei of the squirrel monkey. II. Correlation with output pathways of secondary neurons. J Neurophysiol 58:719-738

Holler S, Straka H (2001) Plane-specific brainstem commissural inhibition in frog second-order semicircular canal neurons. Exp Brain Res 137:190-196

Holstein GR, Martinelli GP, Cohen B (1999) The ultrastructure of GABA-immunoreactive vestibular commissural neurons related to velocity storage in the monkey. Neuroscience 93:171-181

Hudspeth AJ, Corey DP (1977) Sensitivity, polarity, and conductance change in the response of vertebrate hair cells to controlled mechanical stimuli. Proc Natl Acad Sci USA 74:2407-2411

Hudspeth AJ, Jacobs R (1979) Stereocilia mediate transduction in vertebrate hair cells (auditory system/cilium/vestibular system). Proc Natl Acad Sci USA 76:1506-1509

Imagawa M, Graf W, Sato H, Suwa H, Isu N, Izumi R, Uchino Y (1998) Morphology of single afferents of the saccular macula in cats. Neurosci Lett 240:127-130

Ito M, Highstein SM, Fukuda J (1970) Cerebellar inhibition of the vestibulo-ocular reflex in rabbit and cat and its blockage by picrotoxin. Brain Res 17:524-526

Ito M, Sato N, Simpson JI, Udo M (1971) Contribution of mossy fiber-granule cell pathway to the cerebellar-induced delayed inhibition in Deiters neurones. Exp Brain Res 12:223-237

Jensen-Smith H, Gray B, Muirhead K, Ohlsson-Wilhelm B, Fritzsch B (2007) Long-distance three-color neuronal tracing in fixed tissue using NeuroVue dyes. Immunol Invest 36:763-789

Jones C, Chen P (2007) Planar cell polarity signaling in vertebrates. Bioessays 29:120-132

Kevetter GA, Leonard RB, Newlands SD, Perachio AA (2004) Central distribution of vestibular afferents that innervate the anterior or lateral semicircular canal in the mongolian gerbil. J Vestib Res 14:1-15

Korte GE, Mugnaini E (1979) The cerebellar projection of the vestibular nerve in the cat. J Comp Neurol 184:265-277

Lewis ER, Leverenz EL, Bialek WS (1985) The vertebrate inner ear. CRC, Boca Raton 
Li A, Xue J, Peterson EH (2008) Architecture of the mouse utricle: macular organization and hair bundle heights. J Neurophysiol 99:718-733

Lindeman HH (1969) Regional differences in structure of the vestibular sensory regions. J Laryngol Otol 83:1-17

Lorente de No R (1933) Anatomy of the eighth nerve. The central projection of the nerve endings of the internal ear. Laryngoscope 43:1-38

Lowenstein O (1961) Problems concerning the mechanism of the hair cells of the vestibular receptors. Acta Otolaryngol Suppl 163:56-58

Lysakowski A, Minor LB, Fernández C, Goldberg JM (1995) Physiological identification of morphologically distinct afferent classes innervating the cristae ampullares of the squirrel monkey. J Neurophysiol 73:1270-1281

Maklad A, Fritzsch B (1999) Incomplete segregation of endorganspecific vestibular ganglion cells in mice and rats. J Vest Res 9:387-399

Maklad A, Fritzsch B (2002) The developmental segregation of posterior crista and saccular vestibular fibers in mice: a carbocyanine tracer study using confocal microscopy. Brain Res Dev Brain Res 135:1-17

Maklad A, Fritzsch B (2003a) Partial segregation of posterior crista and saccular fibers to the nodulus and uvula of the cerebellum in mice, and its development. Brain Res Dev Brain Res 140:223236

Maklad A, Fritzsch B (2003b) Development of vestibular afferent projections into the hindbrain and their central targets. Brain Res Bull 60:497-510

Matei V, Pauley S, Kaing S, Rowitch D, Beisel KW, Morris K, Feng F, Jones K, Lee J, Fritzsch B (2005) Smaller inner ear sensory epithelia in Neurog 1 null mice are related to earlier hair cell cycle exit. Dev Dyn 234:633-650

Mbiene JP, Favre D, Sans A (1984) The pattern of ciliary development in fetal mouse vestibular receptors. A qualitative and quantitative SEM study. Anat Embryol 170:229-238

Morin F, Dino MR, Mugnaini E (2001) Postnatal differentiation of unipolar brush cells and mossy fiber-unipolar brush cell synapses in rat cerebellum. Neuroscience 104:1127-1139

Mugnaini E, Floris A (1994) The unipolar brush cell: a neglected neuron of the mammalian cerebellar cortex. J Comp Neurol 339:174-180

Naito Y, Newman A, Lee WS, Beykirch K, Honrubia V (1995) Projections of the individual vestibular end-organs in the brain stem of the squirrel monkey. Hear Res 87:141-155

Newlands SD, Perachio AA (2003) Central projections of the vestibular nerve: a review and single fiber study in the Mongolian gerbil. Brain Res Bull 60:475-495

Newlands SD, Purcell IM, Kevetter GA, Perachio AA (2002) Central projections of the utricular nerve in the gerbil. J Comp Neurol 452:11-23

Newlands SD, Vrabec JT, Purcell IM, Stewart CM, Zimmerman BE, Perachio AA (2003) Central projections of the saccular and utricular nerves in macaques. J Comp Neurol 466:31-47

Precht W, Shimazu H (1965) Functional connections of tonic and kinetic vestibular neurons with primary vestibular afferents. J Neurophysiol 28:1014-1028

Purcell IM, Perachio AA (2001) Peripheral patterns of terminal innervation of the vestibular primary afferent neurons projecting to the vestibulocerebellum in the gerbil. J Comp Neurol 433:48-61
Rabbitt RD, Yamauchi AM, Boyle R, Highstein SM (2001) How endolymph pressure modulates semicircular canal primary afferent discharge. Ann N Y Acad Sci 942:313-321

Reichenberger I, Straka H, Ottersen OP, Streit P, Gerrits NM, Dieringer N (1997) Distribution of GABA, glycine, and glutamate immunoreactivities in the vestibular nuclear complex of the frog. J Comp Neurol 377:149-164

Sato F, Sasaki H, Ishizuka N, Sasaki S, Mannen H (1989) Morphology of single primary vestibular afferents originating from the horizontal semicircular canal in the cat. J Comp Neurol 290:423-439

Schwarz DW, Schwarz IE (1986) Projection of afferents from individual vestibular sense organs to the vestibular nuclei in the pigeon. Acta Otolaryngol 102:463-473

Shimazu H, Precht W (1966) Inhibition of central vestibular neurons from the contralateral labyrinth and its mediating pathway. J Neurophysiol 29:467-492

Shojaku H, Sato Y, Ikarashi K, Kawasaki T (1987) Topographical distribution of Purkinje cells in the uvula and the nodulus projecting to the vestibular nuclei in cats. Brain Res 416:100-112

Shotwell SL, Jacobs R, Hudspeth AJ (1981) Directional sensitivity of individual vertebrate hair cells to controlled deflection of their hair bundles. Ann N Y Acad Sci 374:1-10

Si X, Zakir MM, Dickman JD (2003) Afferent innervation of the utricular macula in pigeons. J Neurophysiol 89:1660-1677

Straka H, Dieringer N (1996) Uncrossed disynaptic inhibition of second-order vestibular neurons and its interaction with monosynaptic excitation from vestibular nerve afferent fibers in the frog. J Neurophysiol 76:3087-3101

Straka H, Dieringer N (2000) Convergence pattern of uncrossed excitatory and inhibitory semicircular canal-specific inputs onto second-order vestibular neurons of frogs. Organization of vestibular side loops. Exp Brain Res 135:462-473

Uchino Y, Sato H, Suwa H (1997) Excitatory and inhibitory inputs from saccular afferents to single vestibular neurons in the cat. J Neurophysiol 78:2186-2192

Uchino Y, Sato H, Kushiro K, Zakir M, Imagawa M, Ogawa Y, Katsuta M, Isu N (1999) Cross-striolar and commissural inhibition in the otolith system. Ann N Y Acad Sci 871:162-172

Walberg F, Ottersen OP, Rinvik E (1990) GABA, glycine, aspartate, glutamate and taurine in the vestibular nuclei: an immunocytochemical investigation in the cat. Exp Brain Res 79:547-563

Wersäll J (1961) Vestibular receptor cells in fish and mammals. Acta Otolaryngol Suppl 163:25-29

Wersäll J, Flock A (1963) Physiological aspects on the structure of vestibular endorgans. Acta Otolaryngol Suppl 192:85-89

Wersäll J, Flock A, Lundquist PG (1965) Structural basis for directional sensitivity in cochlear and vestibular sensory receptors. Cold Spring Harb Symp Quant Biol 30:115-132

Wilson VJ (1972) Physiological pathways through the vestibular nuclei. Int Rev Neurobiol 15:27-81

Wylie DR, Lau KL, Lu X, Glover RG, Valsangkar-Smyth M (1999) Projections of Purkinje cells in the translation and rotation zones of the vestibulocerebellum in pigeon (Columba livia). J Comp Neurol 413:480-493

Zakir M, Dickman JD (2006) Regeneration of vestibular otolith afferents after ototoxic damage. J Neurosci 26:2881-2893

Zakir M, Huss D, Dickman JD (2003) Afferent innervation patterns of the saccule in pigeons. J Neurophysiol 89:534-550 